\title{
EDITORIAL
}

\section{Exploring the role of psychology in management research and finding both depth and breadth}

An understanding of the role of psychology as the study of behaviour and mental processes, has become so much a part and parcel of everyday management that is can be easy to forget just how multifaceted a discipline it is. This 3rd edition of Journal of Management \& Organization for 2017 specifically examines some of this depth and breadth through nine papers, which each contribute a distinct view as to the direct link between human behaviour and organizational processes, operations and outcomes. While covering an enormous diversity and richness, the central theme of each of these contributions is that successful management lies in focussing on the human element, not on the work.

Jam, Donia, Raja, and Ling start us on this endeavour with a time-lagged study into perceived organizational politics and overall satisfaction on job stress, interpersonal conflict, job performance and creativity. Perhaps not surprisingly to some, the findings show that levels of workplace politics positively influence job stress - with highly satisfied individuals demonstrating higher levels of creativity and job performance. Before practitioners get too excited and rush off to increase the levels of workplace politicking, it is worth mentioning that the paper also suggests that even highly satisfied individuals engage in interpersonal conflict and experience high stress when workplace politics is high!

The need to adopt an approach which is embedded within individual context is well known in psychology and, as our second paper shows, just as important in guiding organizational strategy. Karatepe and Olugbade's article uses career construction theory to examine whether career adaptability mediates the effect of work social support on career satisfaction and turnover intentions. While the results do suggest that work social support boosts career adaptability and career satisfaction, while it mitigates turnover intentions, the article also suggests that career adaptability triggers turnover intentions (read the paper to find out the authors thoughts as to why!).

The fact that people do not always behave as expected is taken a step further with the paper by Ismail and Gali which takes us into an exploration of the relationship between performance appraisal satisfaction, job stress and work-family conflict. The findings reveal that job stress fully mediates the relationship between performance appraisal satisfaction and work-family conflict. The links made in this study makes between performance appraisal satisfaction and employees' psychological responses extend beyond the workplace to acknowledge the important role nonwork life plays for most of us.

Our fourth article returns us to the world of work while retaining the focus on how we deal with the negative. Here, Bouckenooghe, Raja, Butt, Abbas, and Bilgrami explore the relationships of negative affectivity with both job performance and turnover intentions. Testing the conventional wisdom that negative affectivity is detrimental to both job performance and intentions to leave, the results reveal that there are also functional effects of negative affectivity.

The challenge to conventional wisdom continues with Westerlake, Jordan, and Ramsay's paper questioning the assumption of the psychological contract that both parties come to a mutual agreement about the expectations and obligations of a contract of employment. Using the very aptly named Measure of Employee Entitlement, the paper aims to situate the notion of a sense of entitlement as a factor for further investigation.

The ability of a psychological lens to provide a framework for looking at issues from multiple perspectives and suggest new ways of thinking is then taken a step further with the paper by Hayek, Randolph-Seng, Williams, and Ingram. Drawing on both Conservation of Resources Theory and Cognitive Activation Theory and addressing it to the political skill, the results reveal interesting and 
sometimes unexpected relationships affective and continuance commitment, life satisfaction and political skill.

Drawing different theoretical lenses together is an underlying theme of this issue of Journal of Management \& Organization and it emerges strongly in our seventh paper. Here, Brunetto, Teo, Shacklock, Farr-Wharton, and Shriberg accomplishes the task of uniting Positive Organizational Behaviour and Social Exchange Theory to examine the influence of supervisor-subordinate relationships and the personal resource of psychological capital upon police officers' work outcomes (teamwork, training and affective commitment). The focus on individuals, teams and senior managers makes this a study with powerful implications which extend well beyond the police workforce.

While the issues of ethics and morality were implicit in Brunetto et al.'s paper, they become the explicit focus in De Cremer and Vandekerckhove's. This paper sets out to offer us a comprehensive and complete understanding of the value that people assign to ethics and how it influences their actions and decisions through presenting an approach that is grounded in the behavioural sciences. It is a conceptual paper that will hopefully have you re-thinking your own views as to what constitutes 'good' or 'bad' behaviour and why this is the case.

The need for a management mindset which truly acknowledges the individual contribution and aligns them with strategic goals is the topic of our ninth and last paper. Here, Chowman, Pries, and Mann explore the relationships between human resource management practices and innovation outcomes at the workplace level. The findings indicate workplaces that set strategic goals related to innovation, that motivate their employees, that create opportunity for their employees to act and that make greater use of technology tend to be more persistent innovators.

Overall, the key theme in our collection of papers in this third issue of Journal of Management \& Organization is that the human factor is the essence and core of management. The field of psychology continues to provide key frameworks, notions and concepts leading our exploration of both work, and the individuals, teams and contexts where it is carried out.

Tui McKeown

Editor in Chief

Journal of Management \& Organization 